\title{
PATIENTS' RISK OF CAUSING TRAFFIC VIOLATIONS AND TRAFFIC ACCIDENTS WHILE DRIVING
}

\author{
Nevenka Šestan ${ }^{1}$, Metoda Dodič Fikfak', Zvone Balantič² \\ ${ }^{1}$ Ljubljana University Medical Centre, Clinical Institute of Occupational, Traffic, and Sports Medicine, Ljubljana, Slovenia \\ ${ }^{2}$ Faculty of Organizational Sciences, University of Maribor, Maribor, Slovenia
}

\section{SUMMARY}

Objectives: This study examines whether drivers suffering from epilepsy, chronic alcoholism and/or hazardous drinking, psychoactive substance abuse, other diseases of the nervous system, mental and behavioural disorders, cardiovascular diseases, severe diabetes, and severe eye diseases are at a greater risk of causing traffic accidents and traffic violations than drivers that cause accidents and violations without these diagnoses.

Methods: A case control study was carried out. The cases were drivers checked by a special medical committee in the period observed suffering from the diseases listed above. Matched controls were taken from the cohort of those that caused accidents and violations during the same period observed. The descriptive statistics were followed by calculation of correlations, t-tests and $x^{2}$, and the odds ratio.

Results: Drivers with referrals for diseases of the nervous system are five times more likely to cause a traffic accident compared to controls $(\mathrm{OR}=5.18 ; 95 \% \mathrm{Cl}=2.59-10.34)$; in addition, a high risk is associated with drivers with mental and behavioural disorders $(\mathrm{OR}=3.64 ; 95 \%$ $\mathrm{Cl}=1.91-6.94)$, drivers with epilepsy ( $\mathrm{OR}=1.99 ; 95 \% \mathrm{Cl}=1.01-3.92)$, and drivers addicted to alcohol $(\mathrm{OR}=1.71 ; 95 \% \mathrm{Cl}=1.01-2.89)$.

Conclusion: Drivers suffering from addiction, a disease of the nervous system, or epilepsy are more likely to cause a traffic accident, which is a contribution to the inconclusive findings of previous studies. The multiple reasons for risks of patients suffering from mental and behavioural disorders need to be further investigated.

Key words: traffic accidents, at-risk drivers, alcoholism, epilepsy, mental and behavioural disorders

Address for correspondence: N. Šestan, Ljubljana University Medical Centre, Clinical Institute of Occupational, Traffic, and Sports Medicine, Poljanski nasip 58, 1000 Ljubljana, Slovenia. E-mail: nevenka.sestan@kclj.si

https://doi.org/10.21101/cejph.a4642

\section{INTRODUCTION}

The high number of deaths and injuries due to traffic accidents and substantial damage is a major social and public health problem. The number of deaths and injuries due to traffic accidents justifies this phenomenon as having reached epidemic proportions. Globally, this phenomenon can be labeled a pandemic because it is not limited to individual countries, since it is a worldwide problem typical of all societies with substantial traffic.

In 2011, 30,100 people died on roads in the European Union, which is equivalent to the population of a medium-sized town, and 324,000 people were injured. In the European Union, the social costs of the worst consequences of traffic accidents in 2010 amounted to $€ 130$ billion.

The World Health Organization (WHO) has forecast that 2.34 million people will die in traffic accidents in 2020, compared to $1,183,492$ deaths in 2002. Among the latter, more than half were young people and middle-aged adults. In 2000, traffic accidents were the ninth-leading cause of death and were responsible for $2.8 \%$ of all causes of death and disability. The WHO forecasts that traffic accidents may rank third among all causes of disability in the world in the next few years (1).

Numerous global studies have shown that drivers under the influence of alcohol are involved in more than a quarter of fatal accidents. Drivers under the influence of marijuana are also involved in a share of fatal accidents. Alcohol and marijuana severely impair the ability to drive, and the level of impairment depends on the quantity ingested. Mixing alcohol with marijuana decreases the ability to drive even in quantities that would be negligible if only one substance were taken (2). Researchers have reported on drivers that were prescribed opiates and benzodiazepines and that incurred higher risks of causing traffic accidents (3). These are more frequent among young drivers and on weekends, primarily because of changed behaviour due to drinking alcohol, drug abuse, and lack of sleep (4).

Studies also show that drivers' diseases may represent risk factors for traffic accidents. Some researchers therefore believe that assessing the ability to drive should be included in medical practice, especially for alcoholics and patients with mental and behavioural disorders $(5,6)$.

Researchers report that patients with mental and behavioural disorders are at high risk of causing traffic accidents despite the fact that they generally drive less than the control group (7). As Muršec has stated, mental disorders often intertwine with physical disorders because there is no condition or disorder in medicine whereby patients would not experience mental changes when suffering from a physical disorder. Emergency conditions in psychiatry are conditions of unusual behaviour, mood, and thoughts that have negative effects on patients and other people in the community in various ways (8). 
Studies on drivers with epilepsy often show that they cause traffic accidents less frequently than the drivers in the rest of the population, and that reporting people with epilepsy and suspending their driver's licenses does not decrease the rate of traffic accidents (9). Similar results are also described in a study of differences between the mortality of drivers with epilepsy and cardiovascular diseases in traffic accidents. It showed that deaths of drivers due to epileptic seizures in the US are half as likely as deaths of patients with cardiovascular disorders and diabetes (10). Nonetheless, Australian neurologists, for instance, favour greater restrictions for professional drivers with epilepsy (11).

Diseases of the nervous system, such as chronic pain, consequences of a stroke, injuries to the brain and spinal cord, depression, and dementia are among the most important causes of reduced quality of life. Two large groups of neurological and psychiatric disorders belong to cerebral disorders. Together, they represent the greatest public health issue in Europe and the western world. They have a high incidence, cause acute and chronic health disorders, and impair patients' abilities in everyday life (12). Following a stroke, depression is also frequent, especially if the stroke affects the left hemisphere. Rehabilitation should be similar to that after a myocardial infarction (13). Depression is the most frequent reason for reassessing an individual's driving abilities following a stroke. The abilities affected comprise a complete range of factors (medical, physical, and cognitive) that affect patients' ability to drive (14).

In several European countries, legislation requires medical checkups for all drivers and potential new drivers prior to obtaining a driver's license as a measure for preventing traffic injuries. The goal of these checkups is to ensure that the driver is able to operate a motor vehicle from the health point of view. In Slovenia, this medical checkup is performed by an occupational physician and the conditions are defined by law. Legislation defines people suffering from certain diseases (epilepsy, alcoholism, psychoactive substance abuse, severe chronic diseases, impaired vision, etc.) as risk drivers in advance. Legislation also stipulates that in case of disagreement with the initial health certificate on physical and mental ability to operate motor vehicles, a person can request additional medical checkup performed by a special medical committee (SMC). The decision of this committee is final.

Although it has not been reliably proved so far that drivers with the diagnoses listed above would pose a greater risk than healthy drivers, checkups for such drivers have been carried out on appeal for years. Therefore, the main purpose of this study was to establish whether drivers with the diagnoses listed above present greater risk of causing accidents and violations than those that cause accidents and violations without such diagnoses.

\section{MATERIAL AND METHODS}

\section{Population Observed}

Two populations were included in the study. The first population (cases) consisted of all drivers treated by the SMC from 2000 to 2010. The entire SMC medical documentation of each driver was studied for 11 years. In the medical documentation 25 different variables were observed. The second population (controls) included all drivers that caused traffic accidents and traffic violations in Slovenia during the same period from 2000 to 2010 . The data were obtained from the police.

A case control study was carried out. All drivers examined by the SMC during the period observed and suffering from one of the diagnoses (epilepsy, diseases of the nervous system, psychoactive substance use, alcohol dependence, alcohol abuse, other mental and behavioral disorders, cardiovascular diseases, or severe diabetes) were defined as cases. For each case, the control was defined matched by gender and age from the cohort of persons causing traffic accidents or traffic violations. Because the matching was done individually for each case, the possible overlap of drivers in the pool of cases with the pool of controls is not statistically important.

The statistical processing was carried out using SPSS, version 20 , statistical package. Descriptive statistics followed by calculating correlations between the variables, then by calculating a t-test and $\chi^{2}$ between the cases and controls for each variable and calculation of the odds ratio with univariate logistic regression analysis. The results were controlled for confounding by age, gender, and smoking.

\section{RESULTS}

During the period observed, 5,056,956 traffic violations caused by $1,281,691$ persons and 326,478 traffic accidents caused by 254,292 persons were registered in Slovenia.

Between January 1st, 2000 and December 31st, 2010, the SMC performed 1,556 checkups of 1,353 males and 203 females. The largest age groups were men 50 to 60 years old and women 30 to 40 years old. The average age of men causing violations and accidents was 46.55 , and the average age of women causing violations was 36.43 and accidents 51.71. In the SMC data, the average age of persons causing violations and accidents is higher than the average age of the entire base of all persons in the police database.

The most frequent cause for referral was epilepsy (ICD-10: G40-G43, 41.6\%), which was followed by alcohol abuse (ICD10: F10, 23.6\%) and mental and behavioural disorders (ICD-10: F00-F99, 23.1\%). In 11.4\% of cases, the cause for referral was diseases of the nervous system (ICD-10: G00-G99) and diseases of the eye and adnexa (ICD-10: H00-H59) (15) (Fig. 1).

The analysis of the data by cause for referral to the SMC shows that drivers that abuse alcohol or are alcohol dependent are twice as likely to cause a violation $(\mathrm{OR}=2.12 ; 95 \% \mathrm{CI}=1.55-2.89)$. The results regarding the risk for drivers with mental and behavioural disorders also show the likelihood of causing a violation to be almost three times higher $(\mathrm{OR}=2.78 ; 95 \% \mathrm{CI}=1.80-4.14)$ than for controls, and drivers with epilepsy are moderately more likely to cause a violation $(\mathrm{OR}=1.58 ; 95 \% \mathrm{CI}=1.03-2.41)$ in comparison to those causing a violation without this diagnosis. A similar situation is observed for the group with diseases of the nervous system $(\mathrm{OR}=1.67 ; 95 \% \mathrm{CI}=1.03-2.73)($ Table 1$)$.

Drivers referred for diseases of the nervous system are five times more likely to cause a traffic accident $(\mathrm{OR}=5.18 ; 95 \%$ $\mathrm{CI}=2.59-10.34)$ compared to controls. Mental and behavioural disorders as causes for referral also have a statistically significant influence on the cause of an accident because drivers with this cause for referral are more than three times more likely to actually cause a traffic accident $(\mathrm{OR}=3.64 ; 95 \% \mathrm{CI}=1.91-6.94)$ 


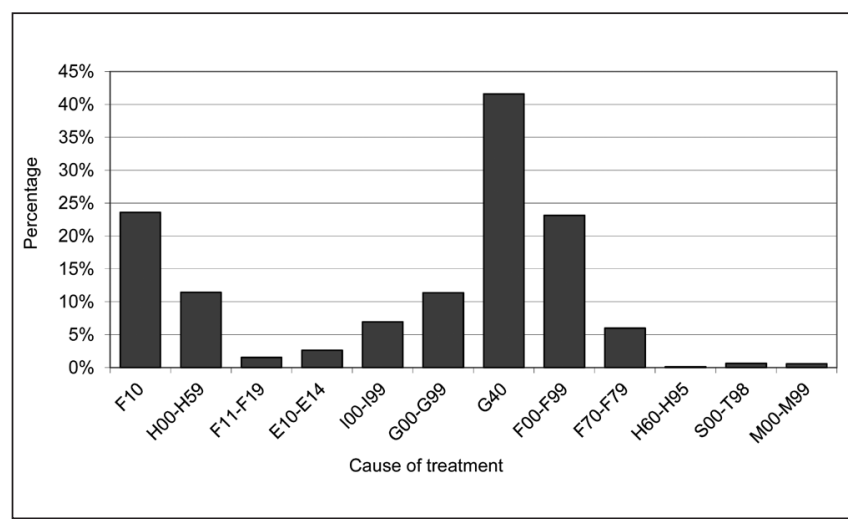

Fig. 1. Percentage of cases treated by cause of treatment by the SMC, 2000-2010.

SMC - Special Medical Committee

International Statistical Classification of Diseases and Related Health Problems: F10: Mental and behavioural disorders due to use of alcohol

H00-H59: Diseases of the eye and adnexa

F11-F19: Mental and behavioural disorders due to use of psychoactive substances E10-E14: Diabetes mellitus

100-199: Diseases of the circulatory system

G00-G99: Diseases of the nervous system

G40: Epilepsy

F00-F99: Mental and behavioural disorders

F70-F79: Mental retardation

H60-H95: Diseases of the ear and mastoid process

S00-T98: Injury, poisoning, and certain other consequences of external causes

M00-M99: Diseases of the musculoskeletal system and connective tissue

compared to controls. Drivers referred for alcohol (dependence or abuse) are almost twice as likely to cause an accident $(\mathrm{OR}=1.71$; $95 \% \mathrm{CI}=1.01-2.89$ ). The odds of transient injuries among those referred are almost three times higher than for controls, but the results are unreliable (Table 2).

\section{DISCUSSION}

The cohort of drivers that caused a violation or accident was intentionally selected as the source for controls rather than all drivers in Slovenia. Thus, both populations observed were matched in such a way that all other factors except diseases that influence the cause of accidents and violations were also matched. This matching of cases and controls is believed to have excluded all

Table 1. Univariate logistic regression, odds ratio for traffic violations by referral cause, 2000-2010

\begin{tabular}{|l|c|c|c|}
\hline Referral cause & OR & $\mathbf{p}$ & $95 \% \mathbf{C l}$ \\
\hline Alcohol (abuse, hazardous drinking) & 2.12 & $<0.001$ & $1.55-2.89$ \\
\hline Psychoactive substance abuse & 0.92 & 0.865 & $0.35-2.42$ \\
\hline Injuries & 1.46 & 0.652 & $0.28-7.59$ \\
\hline Epilepsy & 1.58 & 0.035 & $1.03-2.41$ \\
\hline Mental and behavioural disorders & 2.78 & $<0.001$ & $1.86-4.14$ \\
\hline Diseases of the nervous system & 1.67 & 0.039 & $1.03-2.73$ \\
\hline Psychological cause & 1.17 & 0.655 & $0.59-2.31$ \\
\hline Diabetes & 0.94 & 0.904 & $0.34-2.62$ \\
\hline Cardiovascular disorders & 0.61 & 0.517 & $0.14-2.74$ \\
\hline Diseases of the eye & 1.49 & 0.128 & $0.89-2.52$ \\
\hline
\end{tabular}

Table 2. Univariate logistic regression, odds ratio for traffic accidents by referral cause, 2000-2010

\begin{tabular}{|l|c|c|c|}
\hline Referral cause & OR & $\mathbf{p}$ & $95 \% \mathbf{C l}$ \\
\hline Alcohol (abuse, hazardous drinking) & 1.71 & 0.047 & $1.01-2.89$ \\
\hline Psychoactive substance abuse & 0.55 & 0.573 & $0.07-4.34$ \\
\hline Injuries & 2.77 & 0.261 & $0.47-16.34$ \\
\hline Epilepsy & 1.99 & 0.048 & $1.01-3.92$ \\
\hline Mental and behavioural disorders & 3.64 & $<0.001$ & $1.91-6.94$ \\
\hline Diseases of the nervous system & 5.18 & $<0.001$ & $2.59-10.34$ \\
\hline Psychological cause & 1.46 & 0.523 & $0.46-4.66$ \\
\hline Diabetes & 1.51 & 0.608 & $0.31-7.34$ \\
\hline Cardiovascular disorders & 0.00 & 0.998 & 0.00 \\
\hline Diseases of the eye & 1.38 & 0.506 & $0.54-3.54$ \\
\hline
\end{tabular}

possible systematic mistakes, primarily confounders that influence the cause of accidents and violations. The authors also believe that weather conditions, which might be very important confounding factors, were randomly distributed among all cases and controls or, in other words, the decision to drive in certain weather conditions does not depend on the diagnosis. It was expected that the average age of drivers that had caused violations or accidents and that had been examined by the SMC would be higher than the cohort from the police records, from which the controls were obtained. Because age could affect the results of the study, each control was additionally matched by age and gender with cases during data processing.

The most frequent cause for referral for treatment by the SMC is epilepsy. In the literature, there are completely contradictory data on the risk of drivers with epilepsy causing accidents and violations $(11,16)$. Our findings show that drivers with epilepsy cause violations $60 \%$ more frequently than the controls and that these patients are twice as likely to cause an accident. This result is surprising because epilepsy is most certainly one of the most "controlled" diagnoses; it is treated in detail in road-safety legislation and the SMC regularly monitors these patients and, in line with the legislation, often imposes restrictions. Experts disagree regarding the risk of traffic accidents caused by persons with epilepsy. Persons with epilepsy themselves categorize the inability to drive as one of their greatest problems and believe that driving restrictions for people with epilepsy are too harsh (17) and that an excessive limitation on driving has an unfair impact on individuals' welfare (18). Advocates of the restrictions on driving claim that it is necessary to take into account the fact that epileptic seizures during driving entail greater risk of accidents, injuries, or even death. Therefore, the restrictions in such cases will probably not be lifted. However, more careful consideration should be given to the fact that such risks are predictable to a great extent since they are based on recognizable risk factors, such as relative frequency of epileptic seizures, and especially that $70 \%$ of people with epilepsy do not have epileptic seizures (19). For instance, in the US and in some other countries people with controlled epilepsy can obtain a driver's license without restrictions (18). There are no clear answers; there are about 6,000,000 people with epilepsy in Europe alone and about 300,000 new cases of this disease are identified every year. Therefore, further studies will 
be necessary to help decide whether general driving restriction for people with epilepsy is actually the only reasonable measure or whether it would make sense to consider other more effective measures. The results of this study show the direction further studies should take; that is, to look for a causal relationship between accompanying variables in drivers with epilepsy (e.g., treatment, greater fatigue, level of changes in EEG, and time since the last epileptic seizure) and greater risk for accidents and violations. In this way, the circle of those directly causing accidents and violations would be limited and the restrictions would be imposed on a very limited group of drivers with epilepsy.

This study also confirmed the assumption that drivers that drive under the influence of alcohol are at greater risk of causing a violation as well as an accident. Closer attention should be paid to this population group. Taking into account our results as well as data from the police on the average blood alcohol level of drivers examined in the past few years and the number of drunk drivers, it is clear that legislation is not successful enough. Namely, many studies carried out on those involved in traffic accidents indicate that a high percentage of them are still driving under the influence of alcohol or drugs (20).

In this study, drivers referred for diseases of the nervous system also frequently cause traffic accidents and violations. The people examined by the SMC are mostly elderly with various diseases of the nervous system, except epilepsy, which is treated separately. In this group, drivers after a stroke and patients with Parkinson's disease are most frequently represented, and therefore special care should be applied to this group of drivers. A study of driving abilities during a test drive on the road showed that just over half of test subjects passed the driving test (21).

This study also shows that people with mental and behavioural disorders are almost three times more likely to cause violations and almost four times more likely to cause accidents. In addition, a study by De Las Cuevas and Sanz established that only $16 \%$ of patients with mental and behavioural disorders are capable of driving, and that $84 \%$ of the test subjects do not satisfy at least one of the demands for safe driving (22). Various diagnoses within this group of diseases demand longer treatment, often with various psychotropic drugs. Among this group of diseases, depression is the most frequent. It impairs the physical and mental abilities necessary for safe driving. Researchers have identified the following risk factors for traffic accidents in people suffering from depression: concentration disorders, decreased attention, slowness, extreme fatigue and sleepiness, or bad temper and anger.

A disease in this group with major growing importance is dementia. Drivers with moderate or severe dementia cannot operate a motor vehicle safely because their physical and mental abilities are worse and their reaction is too slow for suitable reactions to traffic conditions or dangers.

Without doubt, numerous opposing results suggest that greater care and more research should be devoted to addiction, other mental and behavioural disorders (by diagnosis), diseases of the nervous system, and epilepsy on the one hand, and, on the other hand, the results of studies should be taken into consideration when planning preventive measures and passing legislation on safe driving. Beyond the shadow of a doubt, developing technology will be of great help in solving at least some of these problems.

\section{CONCLUSIONS}

The results confirm the hypothesis that drivers suffering from alcohol dependence and/or alcohol abuse, epilepsy, mental and behavioural disorders, or diseases of the nervous system are more at risk of causing traffic accidents and traffic violations than drivers that cause accidents and violations without these diagnoses.

\section{Conflict of Interests}

None declared

\section{REFERENCES}

1. Rus-Makovec M, Jakopič J. Driving under alcohol influence and roadtraffic safety: to punish or to treat alcohol non-dependent and dependent drivers? Zdrav Vestn. 2010;79(7-8):582-92. (In Slovenian.)

2. Sewell RA, Poling J, Sofuoglu M. The effect of cannabis compared with alcohol on driving. Am J Addict. 2009;18(3):185-93.

3. Engeland A, Skurtveit S, Mørland J. Risk of road traffic accidents associated with the prescription of drugs: a registry-based cohort study. Ann Epidemiol. 2007;17(8):597-602.

4. Kanaan A, Huertas P, Santiago A, Sanchez JA, Martinez P. Incidence of different health factors and their influence on traffic accidents in the province of Madrid, Spain. Leg Med. 2009;11 Suppl 1:S333-6.

5. Rainio J, Sulander P, Hantula L, Nuutinen J, Karkola K. Diseases and motor vehicle fatalities in Finland in 2001 and 2002. Traffic Inj Prev. 2007;8(3):321-8.

6. Kaasik T, Väli M, Saar I. Road traffic mortality in Estonia: alcohol as the main contributing factor. Int J Inj Contr Saf Promot. 2007;14(3):163-70.

7. Niveau G, Kelley-Puskas M. Psychiatric disorders and fitness to drive. J Med Ethics. 2001;27(1):36-9.

8. Grad A, Mesec A, Mesec Rodi P, Meglič B, editors. Urgent neurology. 2nd ed. Ljubljana: Slovenian associations of neurologists; 2009. (In Slovenian.)

9. McLachlan RS, Starreveld E, Lee MA. Impact of mandatory physician reporting on accident risk in epilepsy. Epilepsia. 2007;48(8):1500-5.

10. Sheth SG, Krauss G, Krumholz A, Li G. Mortality in epilepsy: driving fatalities vs other causes of death in patients with epilepsy. Neurology. 2004;63(6):1002-7.

11. Beran RG, Ainley LA, Beran ME. Opinions, attitudes and practices of Australian neurologists with regard to epilepsy and driving. Intern Med J. 2007;37(4):251-7.

12. Bon J, Koritnik B, Bresjanac M, Repovš G, Pregelj P, Dobnik B, et al. Cost of disorders of the brain in Slovenia in 2010. Zdrav Vestn. 2013;82(3):164-75. (In Slovenian.)

13. Koprivšek J. Depression and distinct population groups. Farm Vestn. 2006;57(4):258-61. (In Slovenian.)

14. Zupan A, Marinček Č. Assessment of driving abilities and car adaptations. Rehabilitacija. 2013;12 Suppl 1:36-44. (In Slovenian.)

15. International statistical classification of diseases and related health problems, tenth revision, Australian Modification (ICD-10-AM)-Tabular list of diseases. 6th ed. Lidcombe, NSW : National Centre for Classification in Health ; 2008.

16. Tomson T, Beghi E, Sundgvist A, Johannessen SI. Medical risks in epilepsy: a review with focus on physical injuries, mortality, traffic accidents and their prevention. Epilepsy Res. 2004; 60(1):1-16.

17. Mavrič M, Zavrnik Č, Bilban M, Grošelj J. Epilepsy and driving. Zdrav Vestn. 2015;84(4):294-305. (In Slovenian.)

18. KrumholzA. Driving issues in epilepsy: past, present, and future. Epilepsy Curr. 2009;9(2):31-5.

19. Martinović, LB. Stigma of epilepsy is worse than the disease. Novilist.hr [Internet]. 2012 Feb 25 [cited 2015 May 10]; Health and beauty. Available from: http://www.novilist.hr/Zivot-i-stil/Zdravlje-ljepota/Zdravlje/ Stigma-epilepsije-gora-je-od-bolesti. (In Croatian.)

20. Christophersen AS, Gjerde H. Prevalence of alcohol and drugs among car and van drivers killed in road accidents in Norway: an overview from 2001 to 2010. Traffic Inj Prev. 2014;15(6):523-31. 
21. Glojar, N. Reintegration of patients in society and workplace after CVI. eSynapsa [Internet]. 2014[cited 2015 Jun 15]; 2014(7). Available from: http://www.sinapsa.org/eSinapsa/stevilke/2014-7/102/Reintegracija bolnikov po možganski kapi v družbi in na delovnem mestu. (In Slovenian.)
22. De Las Cuevas C, Sanz EJ. Fitness to drive of psychiatric patients. Prim Care Companion J Clin Psychiatry. 2008;10(5):384-90.

Received November 23, 2015 Accepted in revised form January 16, 2017 